\title{
Electroformed Gold Dental Crowns and Bridges
}

\author{
THEIR USE WITH COMPOSITE RESIN VENEERS
}

\author{
Matthijs M.A. Vrijhoef, Adam J. Spanauf and Heinz H. Renggli \\ Dental School, University of Nijmegen, The Netherlands \\ Gerard A. Somers \\ Oxy Metal Industries Benelux B.V., 's- Hertogenbosch, The Netherlands \\ Horst L. Wismann \\ I.D.E. Dental Galvanotechnische Geraete, Schliersee, Federal Republic of Germany
}

\section{Continually spiralling costs of dental treatment have encouraged ongoing research into both alternative materials and more efficient processes. One such process finding increasing use in industry is electroforming and recent work in gold electroforming encourages the bope that this technique may find application in dental treatment.}

There is at present a great deal of interest in ways and means of improving productivity in the practice of dentistry. The reasons for this are manifold and are related to the quality, durability and costs of dental restorations and prostheses. Because of the current economic depression, the spotlight has fallen recently upon the question of costs. While substantial variations, and often escalations, in the costs of certain raw materials are factors which affect the costs of dental treatment, they are by no means the most important such factors. Labour costs play by far the most important role in determining costs both in the dentist's consulting room and in the dental technician's laboratory.

This is strikingly illustrated in Figure 1 which gives the relative prices to a patient for a particular porcelain-fused-to-metal crown made from a number of available alloys, the compositions of which have been described in detail by Vrijhoef (1) and by Vrijhoef $e t a l$. (2). Figure 1 makes it very evident that the costs of materials play only a minor role in determining the price to the patient of the finished crown and that the most important factors in this connection are the labour costs of the dental technician and the dentist. Certainly, so far as the cheaper alloys are concerned, material costs are of minor importance and one is forced to the conclusion therefore that the development of new and cheaper materials cannot contribute to any significant lowering of dental laboratory costs.

There seems, in fact, little prospect of reducing laboratory costs as long as production of crowns and bridges is carried out by casting.

This process is an exacting and time-consuming one which involves substantial costs for both equipment and labour. It begins with the taking by the dentist of an impression of the affected teeth and part of the patient's jaw. Using this impression a model is then cast, usually in dental stone. This stone model provides a die, part of which duplicates one or more teeth which have been prepared by the dentist to receive the restoration, and, in some instances, also duplicates an adjoining portion of the gum from which a tooth or teeth have been extracted. The die is used in the subsequent casting, which involves waxing the pattern to provide a mold cavity, constructing a sprue and attaching it to the wax model, investing this with a refractory material, burning out the wax, and a number of other well known steps (3) all of which must be carried out with care and precision. The whole procedure leaves ample room for errors and it is possible for even the most skilled dental technician to spoil an article during its production or to turn out an inferior product.

\section{Electroforming}

Electroforming appears to have considerable potential merit as an alternative to the investment casting technique. Electroplating of gold and its alloys is widely applied in industry to produce deposits with a multitude of colours and chemical compositions upon a variety of substrates (4).

The equipment (Figure 2) and the plating baths employed as well as the technical principles of electroforming are essentially the same as those of electroplating. The main differences between electroplating and electroforming arise from the substantial thicknesses of the deposits which are necessary in the latter. First, plating times are longer. Thus, an electroform of a thickness of $500 \mu \mathrm{m}$ will take 20 times as long to deposit as one of a thickness of $25 \mu \mathrm{m}$ if the same operating conditions are used. Electroforming

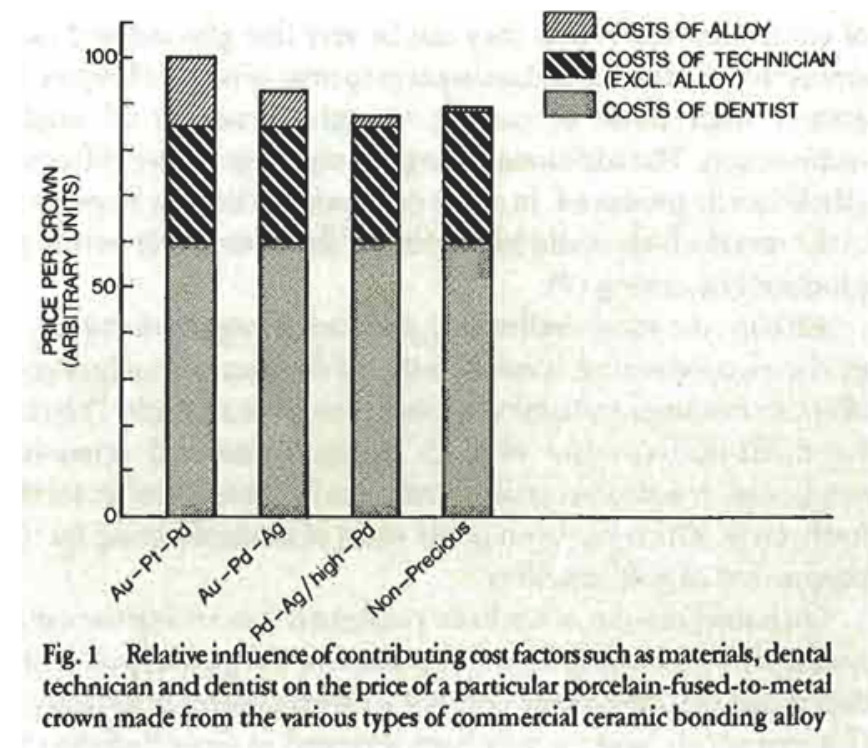




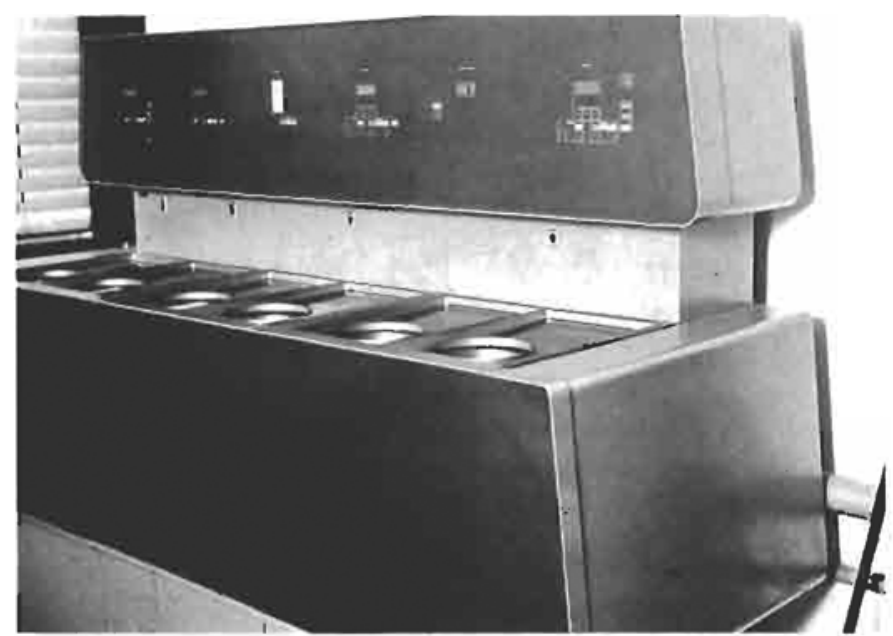

Fig. 2 M.E.M.-System electroforming apparatus as used in this study. Courtesy Oxy Metal Industries (Benelux)

times may therefore be as long as 8 to 12 hours or even longer. Secondly, electroformed deposits are often internally stressed and care must be taken to minimize the internal stresses by choice of an appropriate plating bath and the optimum plating conditions. If this is not done, then an electroform may deform or collapse when its supporting matrix is removed. Thirdly, current density distribution over the cathodic structure during electroforming must be as uniform as possible. This means that attention has to be paid both to the design and the position of an article to be electroformed with respect to the anode, as well as to the choice of a bath with good throwing power

The choice of the plating bath and the operating conditions are also of considerable importance in determining the structure, and, in particular, the grain size of an electroform. A significant feature of electrodeposits is that they can be very fine grained and have strengths, hardnesses and resistances to wear which are frequently greater than those of cast or wrought materials of similar composition. The additional strength is such that an electroformed article can be produced, in many cases, with as little as 30 per cent of the metal which would be required if the same article were to be produced by casting (5).

Perhaps the most challenging problem in regard to the use of gold in electroforming, however, is that of the electroforming of gold alloys of consistent and uniform compositions or caratages. This calls for meticulous control of bath compositions and operating conditions. It is almost certainly the main factor responsible for the limited use which has been made so far of electroforming for the production of gold jewellery.

Such information as has been published concerning the use of gold in electroforming therefore relates for the greater part to the deposition of substantially pure gold. Developments in industry in this area which have recently been reviewed in Gold Bulletin (5), illustrate this point. Recent developments in 18 and 14 carat jewellery applications have been described by Desthomas (6).

Such developments as have taken place in dentistry are also restricted to the electroforming of gold rather than its alloys.

Wismann was granted, as early as 1971 , a patent (3) in which an electroforming process was described whereby inlays, crowns and bridge work were made directly on models or dies. In the process, the electroformed metal sub-structure received a special 'ceramicmetal' coating, which served as a bonding surface for the subsequent coating of the electroform with fused porcelain.

The other main contributor in this field has been Rogers, who has recorded his experience of the use of electroforming in the production of porcelain jacket crowns, porcelain inlays and adaptable electroformed gold margins to cast copings (7-12). Rogers was also granted patents (13) for a process in which gold was electroformed on a (negative) impression of an inlay. Subsequently the (positive) electroformed gold received a porcelain veneer.

Both Wismann (3) and Rogers have claimed considerable time savings for the new procedures as compared with the casting technique.

\section{The Use of Composite Resin Veneers}

When applied to dental restorations with tooth coloured veneers or facings, major disadvantages of the techniques described above are that high temperature and high cost casting and/or porcelain firing procedures are still required. Recently, composite resin veneer materials have become available which have improved properties in comparison with previously used unfilled resin veneer systems which revealed discolouration and wear under oral conditions. It is considered that there is a good possibility of these composite resin materials replacing dental porcelain in a porcelain-fused-to-metal restoration. The costs of producing such composite resin veneers are much lower than current porcelain techniques because only lowtemperature techniques are involved. Described below are the preliminary results of a clinical/laboratory project to test electroformed gold crowns and bridges which were covered with a composite resin veneer.

\section{Materials and Methods}

Eleven crowns and four fixed bridges were made. A total number of twenty teeth (twelve premolars, seven molars, one incisor) and four missing teeth (three premolars, one molar) were involved. Tooth preparation was carried out according to the standard procedures taught at the University of Nijmegen, that is chamfer finishing, line or knife edge finish in the gingival areas; if possible, tooth preparation ended above or at the gingival margins. Standard elastomer impressions were taken of the teeth prepared, while the field of operation was isolated using cotton rolls and vacuum ejector. A full impression tray with waxstops was used. If necessary, a standard gingival retraction technique was applied. After taking the impression a stone model was cast. 
In our electroforming procedure, termed the MicroElectroformed-Metal (M.E.M.)-System, a low melting alloy was used to create an exact duplication rather than electroforming directly onto the stone model or die as described by Wismann (3). In the latter case the entire model or die was covered wirh a resin spray and the surface of the cavity preparation was metallized by means of silver, copper or graphite paint. The disadvantage of such a technique is that contamination through incorrect coverage of the resin paint can affect the performance of the plating solution. Furthermore, stresses in the conductive paint can result in a deformed electroformed structure. In the M.E.M.-System, the duplicate alloy model or die was covered with a special stop-off lacquer up to the margin of the preparation or design. The exposed metal surface was then given an electrodeposited layer of nickel or copper, not only to avoid contamination of the gold bath by the low melting alloy substrate, but also to allow sufficient space for the bonding cement. In the case of a nickel layer, a Wood's type of solution, including brightening agents, was used under the following conditions: Nickel concentration $75 \mathrm{~g} / \mathrm{l}$, solution $\mathrm{pH}$ 3.5-4.5, operating temperature $60^{\circ} \mathrm{C}$, current density $4 \mathrm{~A} / \mathrm{dm}^{2}$. For copper a cyanide electrolyte was used as follows: copper concentration $60 \mathrm{~g} / \mathrm{l}$, solution $\mathrm{pH}$ alkaline, operating temperature $60^{\circ} \mathrm{C}$, current density $4 \mathrm{~A} / \mathrm{dm}^{2}$. A pure gold electroform was then produced on the nickel or copper layer from a sulphite-based electrolyte at a gold concentration of $10 \mathrm{~g} / \mathrm{l}$, bath temperature of $58^{\circ} \mathrm{C}$ and a plating current density of $0.5 \mathrm{~A} / \mathrm{dm}^{2}$. Depending upon

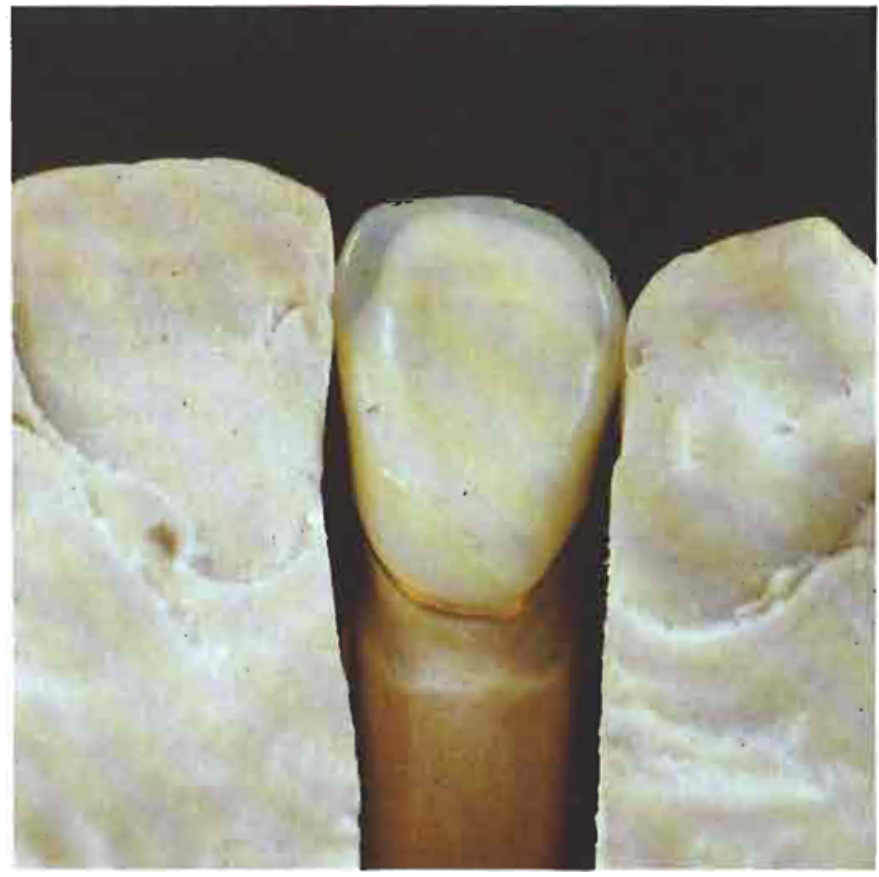

Fig. 3 Palatinal view of an electroformed anterior crown placed on its stone model
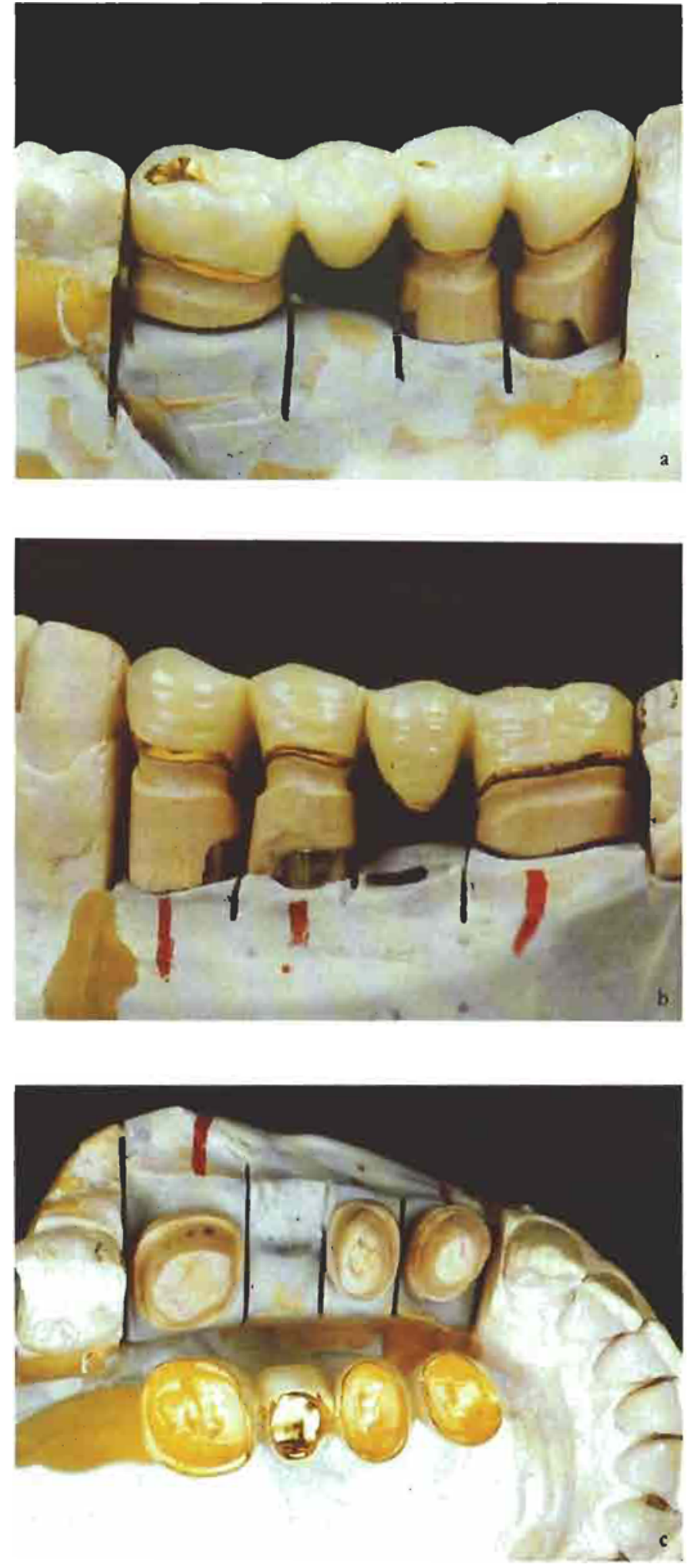

Fig. 4 Example of an electroformed four-unit bridge before placement in the mouth: (a) lingual view (b) facial view (c) bottom view showing the interior 

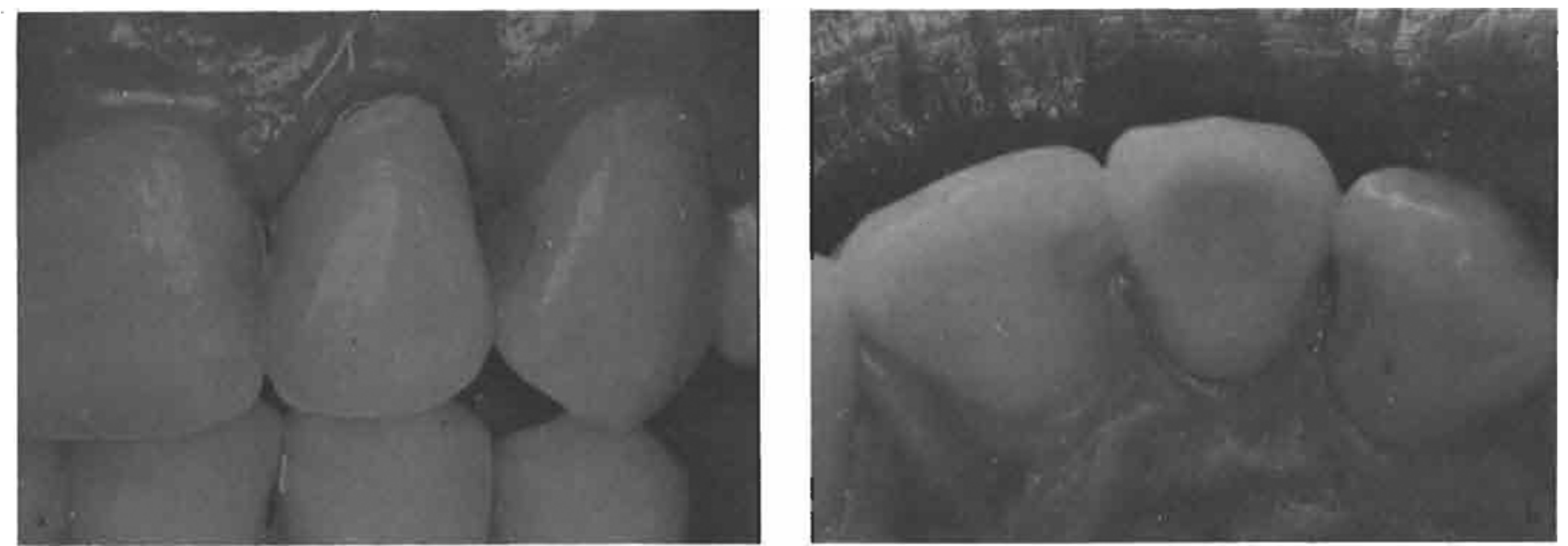

Fig. 5 Crown shown in Figure 3 under oral conditions: (a) facial view (b) palatinal view

the surface texture of the gold electroform required brightening agents may or may not be added to the solution for this step. The low melting alloy and the nickel or copper layer were subsequently removed by means of melting and chemical stripping respectively. The intermediate layer has the advantage at this stage of preventing the formation of detrimental alloy phases between the gold and the components of the low melting alloy. All standard electroforming procedures such as surface activation before electroforming and the forming of a textured or a glossy surface were carried out lege artis. All dental laboratory techniques necessary to produce a crown or bridge have been described adequately by Wismann (3).

Lastly, the hollow parts, such as connectors and pontics, were filled with composite resin material, with the outer parts of the metal substructure receiving a standardized composite resin veneer.

\section{Results}

Some examples of electroformed crowns and bridges are depicted in Figures 3 to 6 . During cementing of the crowns and bridges no problems were encountered. The fit of the respective crowns and bridges prior to and after cementation was tested by means of a dental mirror and probe. All buccal (facial), lingual (palatinal) and proximal margins were found to be clinically acceptable. Occlusion was checked by means of articulation paper and the individual feeling of the patients. Noobvious discrepancies were observed. Only in one case was a slight readjustment of occlusion and articulation necessary. In all other cases occlusion and articulation requirements were completely satisfied.

Contact areas and embrasures were easily accessible in order that the individual patients could keep the interdental spaces clean. The

Fig. 6 Bridge shown in Figure 4 under clinical conditions: (a) directly after placement (b) showing separation of composite veneer
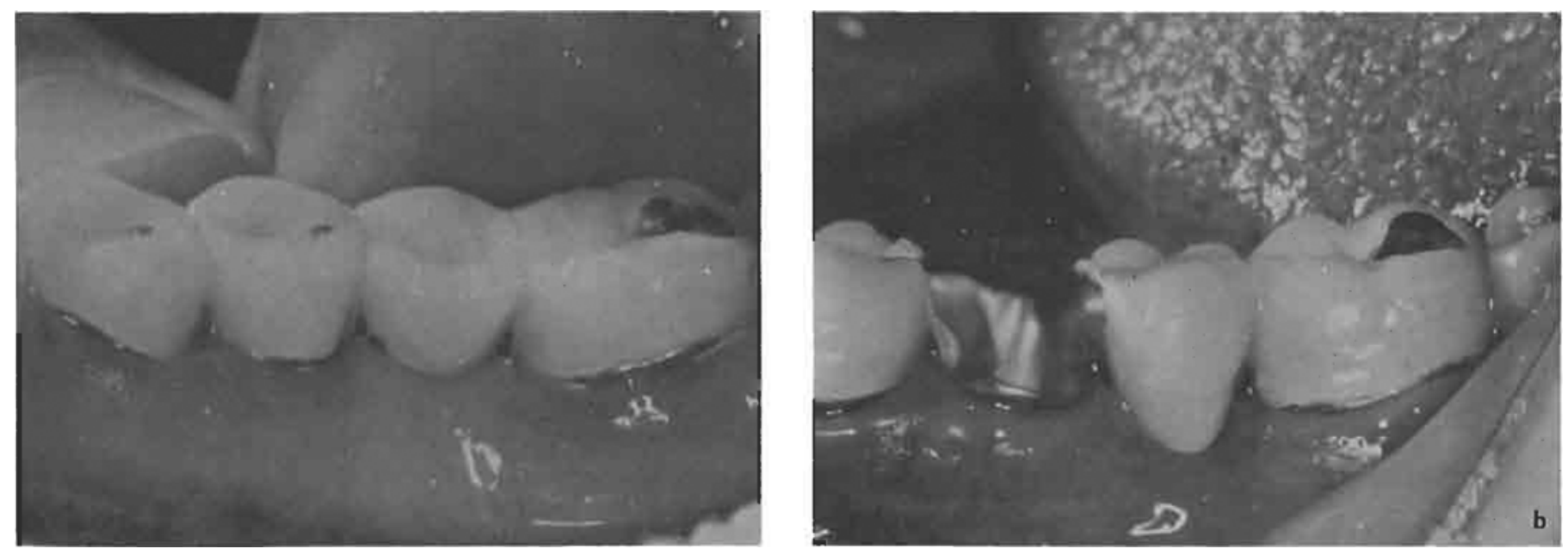
aesthetics of the system were in general very well accepted by the patients. After a relatively short service time problems were encountered with the bridges with regard to the metal-composite resin-compatibility. Although microporosity was created on the gold surface adjacent to the composite resin by using a low or zero concentration of brightener in the gold electrolyte, retention apparently was insufficient because the resin veneer started to fracture and after a while even separated from the metal substrate (Figure 6). Patients with the highest occlusal forces revealed these problems after approximately one to three months. One patient did not show up any fracture of the composite veneer due to the fact that no opposing teeth were present. Consequently, no occlusal forces were applied. Some time later crowns also showed the same compatibility problems in the sense that the resin either became dislodged 'spontaneously' under the influence of the oral forces or could be removed easily by means of a dental probe. It should be stressed that in all cases no special problems associated with the metal parts per se could be distinguished.

\section{Further Developments}

From the results obtained to date it is evident that the electroformed gold parts of the crowns and bridges are adequate regarding their adaptation to the remnant hard tissues. The marginal fit is as good as the impression provided by the dentists. The new M.E.M.-System makes it possible to establish a cement space, which is well controlled to a few micrometres for the various cements used in dentistry. The problems of cracking and separation of the composite veneer from the electroformed gold surface are associated with two contributing factors. The first is the poor retention of resin in the bonding surface, and the second is a result of the limited mechanical properties of the original gold electroform used in the clinical trials described above, leading to poor rigidity and consequent susceptibility of the composite veneer to spalling.

In recent work on the M.E.M.-System carried out in the I.D.E. research laboratories (14) the veneer separation problem has been entirely eliminated. Tests on commonly used gold alloys bonded with a commercial fused porcelain have shown these systems to have maximum shear strengths of approximately $30 \mathrm{MN} / \mathrm{m}^{2}$. The bonding surface in the M.E.M.-System has been improved to give retention depths of from 1 to over $50 \mu \mathrm{m}$ using electrofotmed gold bonded to a composite resin with a specially developed bonding agent. The mechanical properties of the gold electroform have also been significantly improved ('Table I) by modifying the operating conditions of the electrodeposition bath.

The modulus of the new electroformed gold is above the minimum shown by proprietary gold casting alloys and gives the restorations the required rigidity. The higher hardness of the modified gold makes it possible to prepare the occlusal surface in metal rather than composite veneer, which adds to the stability of a bridge and to the wear resistance of the occlusal surface of the restoration. The improved M.E.M.-System is presently undergoing
Table I

Mechanical Properties of Electroformed Gold as Used for Dental Crowns and Bridges

\begin{tabular}{l|c|l}
\hline \multicolumn{1}{c|}{ Property } & $\begin{array}{l}\text { Used in } \\
\text { original } \\
\text { clinical } \\
\text { tests }\end{array}$ & $\begin{array}{l}\text { Deposition conditions } \\
\text { modified (15). New } \\
\text { clinical test underway } \\
\text { at time of writing }\end{array}$ \\
\hline Modulus Elasticity $\left(\mathrm{GN} / \mathrm{m}^{2}\right)$ & 60 & 77 \\
Yield Strength $\left(\mathrm{MN} / \mathrm{m}^{2}\right)$ & 310 & 460 \\
Tensile Strength $\left(\mathrm{MN} / \mathrm{m}^{2}\right)$ & 420 & 460 \\
Elongation (\%) & 3.4 & $<1$ \\
Vickers Hardness & 143 & 247
\end{tabular}

new clinical tests the results of which will be reported in due course, and should it fulfill all requirements as expected it will greatly increase the accuracy and quality of gold dental restorations. It will also help to keep the technical fraction of restoration fees at a relatively acceptable level compared with the classical casting technique.

\section{References}

1 M.M.A. Vrijhoef, Quintessence Internat., 1982,13, 987-995

2 M.M.A. Vrijhoef, E.L. Lourens, A.J. Spanauf and J.M. van der Zel, Quintessence Dent. Technol., 1983, 7, 311-314

3 H.L. Wismann, U.S. Pat. 3,567,592 (1971)

4 'Gold Plating Technology', Edited by F.H. Reid and W. Goldie, Electrochemical Publications, Ayr, 1974

5 D. Withey, Gold Bull., 1983, 16, (3), 70-75

6 G. Desthomas, Aurum, 1983, 14, 19-26 and 15, 17-21

7 O.W. Rogers, Austral. Dent.J., 1970, 15, (4), 316-323

8 O.W. Rogers, Austral. Dent.J., 1976, 21, (6), 479-487

9 O.W. Rogers and B.W. Amstrong, J. Prosthet. Dent, 1961, 11, (5), 959-966

10 O.W. Rogers, Austral. Dent. J., 1980, 25, (1), 1-6

11 O.W. Rogers, Austral. Dent. J., 1979, 24, (3), 163-170

12 O.W. Rogers, Austral. Dent. J., 1977, 22, (2), 100-106

13 O.W. Rogers, U.S. Pat. 3,997,637 (1976); U.K. Pat. 1502813 (1978)

14 I.D.E. Res. Rep, 20, 1983

15 Oxy Metal Ind., U.S. Pat. 3,787,463 (1974) 